\title{
Dental age estimation in a Brazilian adult population using Cameriere's method
}

\section{Alana de Cássia Silva AZEVEDO(a) Nathalia Zanini ALVES(a) Edgard MICHEL-CROSATO(a) Marcos ROCHA ${ }^{(a)}$ Roberto CAMERIERE ${ }^{(b)}$ Maria Gabriela Haye BIAZEVIC(a)}

(a) Universidade de São Paulo - USP, Faculdade de Odontologia - FO, Departamento de Odontologia Social, São Paulo, SP, Brazil.

(b) University of Macerata, Department of Legal Medicine, AgEstimation Project, Macerata, Italy.
Declaration of Interests: The authors certify that they have no commercial or associative interest that represents a conflict of interest in connection with the manuscript.

\section{Corresponding Author:}

Maria Gabriela Haye Biazevic

E-mail: biazevic@usp.br

DOI: 10.1590/1807-3107BOR-2015.vol29.0016

Submitted: Apr 23, 2014

Accepted for publication: Sep 08, 2014

Last revision: Nov 24, 2014
Abstract: The objectives of this study were to develop a specific formula to estimate age in a Brazilian adult population and to compare the original formula from Cameriere to this Brazilian formula. The sample comprised 1,772 periapical radiographs from 443 subjects (219 men, 224 women) that were organized into 12 groups according to sex (men or women) and age (20-29, 30-39, 40-49, 50-59, 60-69, and 70 years and older). The films were analyzed using the criteria described by Cameriere et al. (2004) and Adobe Photoshop ${ }^{\circledR}$. We obtained a mean error of $8.56(S D=5.80)$ years for tooth $13,7.99(S D=5.78)$ years for tooth $23,8.38(\mathrm{SD}=6.26)$ years for tooth 33 , and $8.20(\mathrm{SD}=6.54)$ years for tooth 43 . When teeth were combined in the analysis, we observed lower mean errors. The Brazilian formula developed from this sample group was more accurate than Cameriere's formula. However, other factors must be considered to improve age estimates in adults.

Keywords: Forensic Sciences; Forensic Dentistry; Age Determination by Teeth.

\section{Introduction}

Since 2000, age estimation of living adults has become increasingly common. ${ }^{1}$ Age estimates are important for civil and criminal cases, in the absence of valid identification documents, for criminals who refuse to provide their true age, and for issues related to immigration and asylum requests to foreign countries. ${ }^{2,3,4,5}$ Therefore, the need for accurate age estimation techniques and the data required to perform these estimates in living individuals has increased. ${ }^{6,7}$

Determining the age of a living person often requires a multidisciplinary approach that involves anthropology, forensic medicine, forensic dentistry, and radiology. ${ }^{3,8}$ In forensic dentistry, techniques have been developed based on the correlation between age and dental structures. ${ }^{9}$ Some of these techniques estimate age from extracted teeth, ${ }^{10}$ but these are too invasive for living subjects.

According to Cunha et al., ${ }^{3}$ tooth development is already complete in adults individuals, so higher discrepancies are observed between their physiological and chronological ages. Hence, it is difficult to estimate age in adults because techniques that are based on degenerative processes are not as accurate as those that are based on tooth development. ${ }^{11}$

Testing different age estimation techniques in various population groups can determine their validity. The best methods for age estima- 
tion are not necessarily those with lower standard deviations, but those that have been tested in several populations, are appropriate for the specific situation, and are easily applicable, rapid, and inexpensive. ${ }^{3}$ High-accuracy age estimates are achieved when specific methods and equations are used in specific population groups..$^{12,13}$

Cameriere t $_{\text {al. }}{ }^{14}$ introduced a method for assessing chronological age based on the correlation between age and the pulp/tooth area ratio on single-rooted teeth. One study ${ }^{15}$ tested the accuracy of this method in a Brazilian sample of children (5-15 years), but no study has tested its accuracy in Brazilian adults.

The objectives of this study were to develop a specific formula to estimate age in a Brazilian adult population and to compare the formula described by Cameriere et $a l .{ }^{14}$ to the Brazilian formula by evaluating the correlation between age and the pulp/tooth area ratio in canines.

\section{Methodology}

The study sample consisted of 1,772 digital periapical radiographs from 443 individuals. Subjects were divided into 12 groups according to sex (female or male) and age (20-29, 30-39, 40-49, 50-59, $60-69$, and 70 years and older). Each age group included 80 participants ( 40 men and 40 women), except for the group of subjects aged 70 years and older because we were unable to reach the desired sample size of 80 . Thus, 24 women and 19 men aged 70 years or older were included in this group.

The inclusion criterion was having 4 healthy permanent upper and lower canines. Thus, we excluded patients who had endodontic treatment, a removable prosthesis, orthodontic appliances, restored canines, rotated teeth, dental caries, tooth wear, or supernumerary canines. The World Dental Federation (FDI) criteria for canines were adopted. All periapical radiographs were collected at a radiology center in the city of São Paulo, Brazil. The radiographs were obtained using an X Ray Timex 70E system (Gnatus ${ }^{\circledR}$, Ribeirão Preto, Brazil) at $70 \mathrm{kVp}$ and $7 \mathrm{~mA}$. The exposure time varied from 0.6 to $0.8 \mathrm{~s}$, and an indirect system of digital image capture was used.

Before commencing the analyses of the radiographs, the observers underwent training exercises.
An inter-observer analysis was performed, and some periapical radiographs that were part of the study were evaluated independently (20 participants, 80 periapical radiographs) by 2 observers. The observers performing the image analysis were blinded to the chronological ages of the subjects.

Each image was saved in a high-resolution JPEG format as described by Cameriere et al. ${ }^{14}$ and they were then imported into Adobe ${ }^{\circledR}$ Photoshop ${ }^{\circledR}$ CS5 software (Adobe Systems, San Jose, California, USA). The JPEG file was opened and enlarged. We performed size, brightness, and contrast adjustments if required. The polygonal lasso tool was used to outline the canine and pulp structures after selecting a minimum of 20 and 10 points, respectively (Figures 1 to 3). ${ }^{14}$ To determine the number of pixels in the tooth and pulp outline layers, a histogram palette was activated, the RGB channel was selected, and the specific layer was then selected. The histogram showed the number of pixels corresponding to each selected layer of the pulp and canine (Figures 4 and 5).

Age was estimated using the 3 equations published by Cameriere et al. ${ }^{16}$ as follows: the first for the

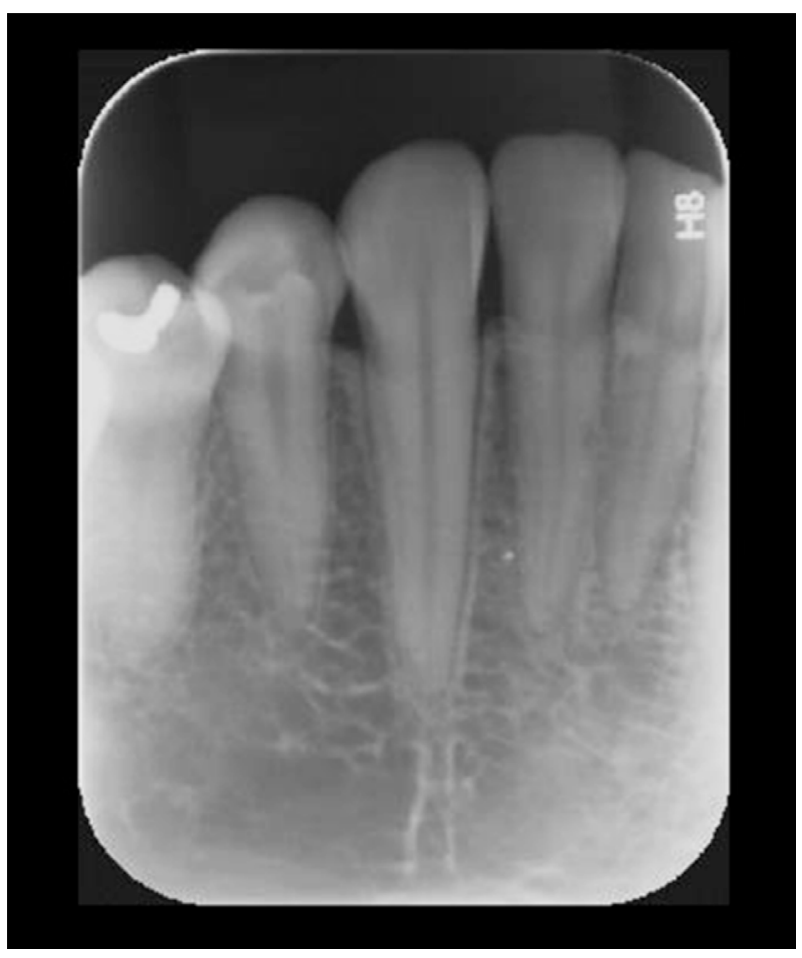

Figure 1. A periapical radiograph imported into Adobe ${ }^{\circledR}$ Photoshop ${ }^{\circledR}$ CS5. We selected the lasso polygonal tool from the tool bar. 


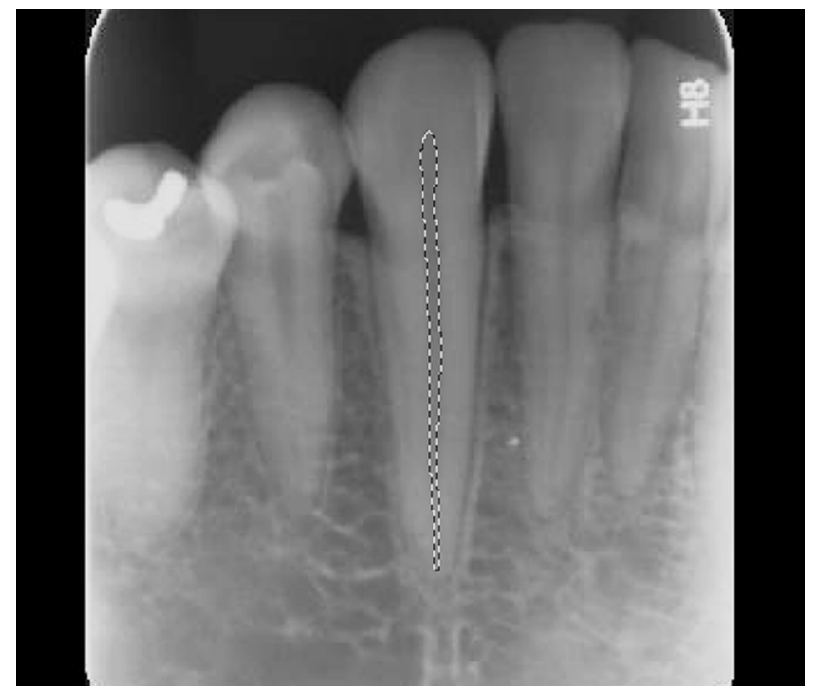

Figure 2. Outline of the pulp structure.

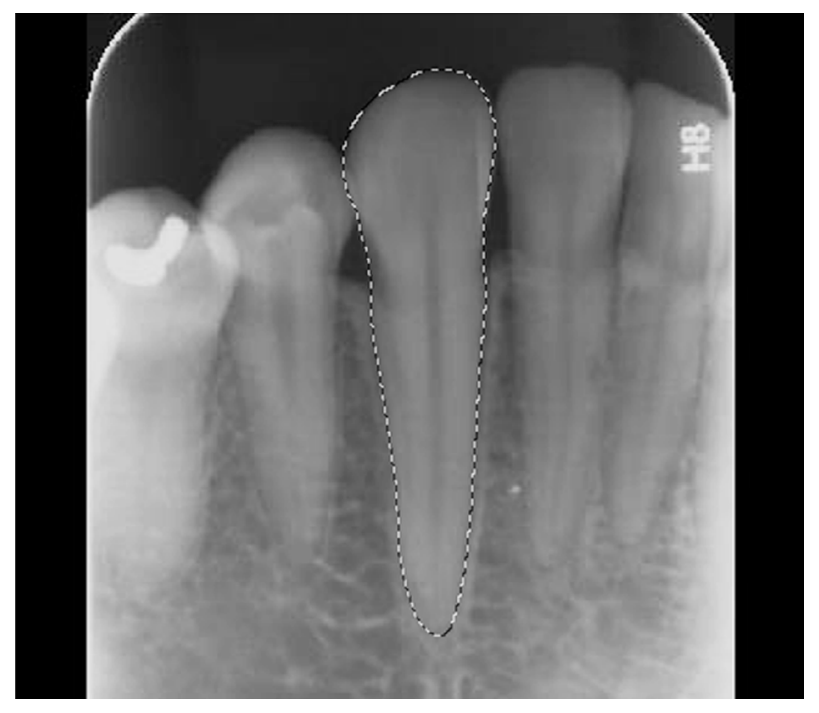

Figure 3. Outline of the canine tooth.

upper canines (1), the second for the lower canines (2), and the last for both upper and lower canines (3). The numbers of pixels comprising the tooth and pulp were required to perform age estimates.

1. Upper canine: Age $=99.937-532.775 \times$ (pulp pixels/upper canine pixels);

2. Lower canine: Age $=89.456-461.873 \times($ pulp pixels/lower canine pixels);

3. Both canines: Age $=114.624-431.183$ (pulp pixels/ upper canine pixels) $-456.692 \times$ (pulp pixels/lower canine pixels) $+1798.377 \times$ (pulp pixels/upper canine pixels $) \times($ pulp pixels/lower canine pixels $)$.
Figure 4. Use of a histogram to verify the number of pixels in the pulp.

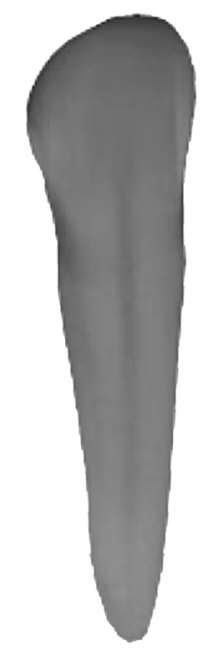

Figure 5. Use of a histogram to verify the number of pixels in the canine.

The age was obtained after evaluating the images, and these values were compared to the actual age of the subjects. Subsequently, a Brazilian formula was developed using the obtained data.

Descriptive statistics were used to measure differences between the real age (RA) and estimated age (EA). A linear regression analysis was performed to evaluate the correlation between the chronological age and the tooth and pulp measurements. Data were organized using Excel spreadsheets, and STATA 13.0 (StataCorp, College Station, Texas, USA.) was used to perform the analysis. 
This study was performed in accordance with the ethical standards on human experimentation as defined in the Helsinki Declaration. Before initiation of this study, the project was approved by the Universidade de São Paulo - USP, School of Dentistry Ethics Committee (process number 116/11).

\section{Results}

We enrolled 443 subjects in this study (1,772 periapical radiographs), including 219 women and 224 men. We excluded 124 radiographs as described above, so the study was performed using 1,648 periapical radiographs.

In most age groups (20-29, 30-39, 40-49, 50-59, and 60-69 years), the sample size included 40 women and 40 men; however, in the group of subjects aged 70 years and older, the desired sample size could not be obtained, so 19 men and 24 women were included in this group.

The RA of the subjects ranged from 20 to 87 years, with a mean age of 47.29 years and a median age of 45.95 years. The intra- and inter-observer intra-class correlation values were $0.742(0.598-0.835)$ and 0.874 (0.689-0.934), respectively.

The Brazilian formula used for dental age estimates was as follows:

4. Upper canine: Age $=94.706-465.358 \times$ (pulp pixels/upper canine pixels);

5. Lower canine: Age $=99.409-503.726 \times($ pulp pixels/lower canine pixels);

6. Both canines: Age $=122.026-471.568 \times($ pulp pixels/upper canine pixels) $-486.891 \times$ (pulp pixels/lower canine pixels $)+2122.427 \times($ pulp pixels/upper canine pixels) $\times$ (pulp pixels/lower canine pixels).

The results $(13,23,33$, and 43$)$ of the RA and EA obtained using the original formula by Cameriere $(\mathrm{OF})$, the EA using the Brazilian formula (BF), and comparisons of RA obtained using the 2 formulas are shown in Table 1. Differences were observed between the OF and BF ( $p=0.001)$, and the BF was more precise.

The comparison between the RA and EA obtained using the $\mathrm{OF}$ and $\mathrm{BF}$ for the right and left sides of the mouth and the added information for tooth numbers 13, 43, 23, and 33 are shown in Table 2. Differences were observed between the OF and $\mathrm{BF}(p=0.001)$, and the BF was more precise. Finally, the comparison of RA obtained using the BF between different age groups is shown in Table 3.

\section{Discussion}

The need to estimate the age of living adults is increasing in forensic odontology. The methods of age estimation that were described by Cameriere $e t$ al. ${ }^{14}$ and Kvaal et al. ${ }^{17}$ used non-invasive approaches, and the measurements they made on radiographs were ethically obtained. Kvaal et al. ${ }^{17}$ used linear measurements, whereas Cameriere et al..$^{14}$ used area measurements to measure the pulp/tooth ratio.

Panoramic and periapical radiographs have been used to evaluate the correlation between the tooth and pulp to facilitate dental age estimates. Several studies have used orthopantomographs, ${ }^{14,18,19}$ but we used periapical radiographs in this study because they produced more reliable data with lower chances of superimposition. ${ }^{4,18,20,21,22,23,24}$

One of the difficulties we encountered was achieving the desired sample size because all radiographs did not show 4 healthy canines. This issue was more common in patients aged 60 years and older. The last Brazilian National Oral Health Survey found that $68.8 \%$ of Brazilian adults required a prosthesis, and those aged 65 to 74 years had an average of 27.5 teeth with caries experience (DMFT index). A factor that further contributed to this situation was the value of "M" (missing teeth) in the DMFT index. ${ }^{25}$

The inter- and intra-observer values showed that repeated measurements were consistent. This finding was similar to other studies. ${ }^{719,20,21,22,23,24}$

Studies that used the method reported here ${ }^{14,18,22,23,24}$ showed that sexual dimorphism did not significantly influence age estimation equations; hence, we did not evaluate the sexes separately.

Using dental radiographs to determine the EA in Italian and Portuguese Caucasian subjects showed that the mean error between the RA and the EA was typically lower than 5 years. ${ }^{14,20,26}$ Our study was performed in a Brazilian population, and the mean error using the same technique and formula ${ }^{14}$ was higher with a variation of 7.96 to 9.68 years. 
Table 1. A descriptive analysis and comparisons among real ages (RA) and estimated ages (EA) by performing evaluations of the canines.

\begin{tabular}{|c|c|c|c|c|c|c|}
\hline Variables & $\mathrm{n}$ & Mean & SD & Min & Max & $p$ \\
\hline \multicolumn{7}{|c|}{13} \\
\hline RA & 443 & 47.29 & 15.99 & 20.42 & 87.58 & \\
\hline EA (OF) & 386 & 42.27 & 11.71 & 9.78 & 78.52 & \\
\hline $\mathrm{EA}(\mathrm{BF})$ & 386 & 44.33 & 10.23 & 15.96 & 76.00 & \\
\hline$E A(O F) \times R A$ & 386 & 8.55 & 6.31 & 0.05 & 35.13 & $p=0.001$ \\
\hline$E A(B F) \times R A$ & 386 & 8.56 & 5.80 & 0.09 & 32.81 & $p=0.001$ \\
\hline $\mathrm{EA}(\mathrm{BF}) \times \mathrm{EA}(\mathrm{OF})$ & 386 & 2.19 & 1.29 & 0.00 & 6.18 & $p=0.001$ \\
\hline \multicolumn{7}{|c|}{23} \\
\hline RA & 443 & 47.29 & 15.99 & 20.42 & 87.58 & \\
\hline $\mathrm{EA}(\mathrm{OF})$ & 383 & 41.58 & 11.69 & 14.00 & 75.60 & \\
\hline $\mathrm{EA}(\mathrm{BF})$ & 383 & 43.74 & 10.21 & 19.64 & 73.45 & \\
\hline EA (OF) x RA & 383 & 8.13 & 6.19 & 0.002 & 32.22 & $p=0.001$ \\
\hline$E A(B F) \times R A$ & 383 & 7.99 & 5.78 & 0.02 & 30.08 & $p=0.001$ \\
\hline$E A(B F) \times E A(O F)$ & 383 & 2.27 & 1.30 & 0.04 & 5.64 & $p=0.001$ \\
\hline \multicolumn{7}{|c|}{33} \\
\hline RA & 443 & 47.29 & 15.99 & 20.42 & 87.58 & \\
\hline $\mathrm{EA}(\mathrm{OF})$ & 438 & 41.93 & 12.50 & 13.86 & 99.94 & \\
\hline $\mathrm{EA}(\mathrm{BF})$ & 438 & 47.03 & 11.97 & 16.96 & 79.34 & \\
\hline$E A(O F) \times R A$ & 438 & 9.68 & 7.50 & 0.00 & 44.25 & $p=0.001$ \\
\hline$E A(B F) \times R A$ & 438 & 8.38 & 6.26 & 0.02 & 38.57 & $p=0.001$ \\
\hline $\mathrm{EA}(\mathrm{BF}) \times \mathrm{EA}(\mathrm{OF})$ & 438 & 5.94 & 3.56 & 3.10 & 43.96 & $p=0.001$ \\
\hline \multicolumn{7}{|c|}{43} \\
\hline RA & 443 & 47.29 & 15.99 & 20.42 & 87.58 & \\
\hline EA (OF) & 441 & 41.51 & 10.90 & 13.64 & 68.34 & \\
\hline $\mathrm{EA}(\mathrm{BF})$ & 441 & 47.12 & 11.89 & 16.72 & 76.38 & \\
\hline$E A(O F) \times R A$ & 441 & 9.53 & 7.26 & 0.013 & 44.36 & $p=0.001$ \\
\hline$E A(B F) \times R A$ & 441 & 8.20 & 6.54 & 0.01 & 38.69 & $p=0.001$ \\
\hline $\mathrm{EA}(\mathrm{BF}) \times \mathrm{EA}(\mathrm{OF})$ & 441 & 5.61 & 0.99 & 3.08 & 8.04 & $p=0.001$ \\
\hline
\end{tabular}

13: Upper right canine; 23: Upper left canine; 33: Lower left canine; 43: Lower right canine; SD: Standard deviation; Min: Minimum; Max: Maximum; RA: Real age; EA: Estimated age; OF: Original formula; BF: Brazilian formula.

Given that some studies have recommended adjustments and specific formulas for different populations, ${ }^{3,12,16}$ we developed a formula for Brazilian populations. We observed a lower mean error in age estimates (7.99 to 8.56 years) using this formula than those determined using the original formula. This finding is similar to another study ${ }^{4}$ that used a specific formula for an Indian population. On the other hand, another study ${ }^{22}$ showed that it is possible to use the same formula for age estimates in both Italian and Portuguese populations. However, it is necessary to highlight that both the original and Brazilian formulas used in this study have incorporated biases. Therefore, it is necessary to consider using additional methods when estimating age in these groups.
When more than one canine was evaluated (the left and right side), we found the lowest mean bias. Thus, to improve the accuracy of the data it would be useful to consider more teeth when performing age estimates. This finding is consistent with reports from other studies. ${ }^{16,21}$

The age estimates were less variable in adults aged 40-49 years, with a lower observed mean error (ME = 6.08-6.87; $\mathrm{SD}=4.04-4.83)$; therefore, this method improved the accuracy of age estimates in this group. The relationship between the pulp and central incisors in individuals aged 41-50 years was evaluated in another study, and compared to the RA of 47.18 years, the mean estimated age was 47.17 years. ${ }^{24}$ Saxena ${ }^{18}$ evaluated a group of subjects aged $41-50$ years, 
Table 2. A descriptive analysis and comparisons among real ages (RA) and estimated ages (EA) by evaluating right (13 and 43 ) and left canines (23 and 33).

\begin{tabular}{|c|c|c|c|c|c|c|}
\hline Variables & $n$ & Mean & SD & Min & Max & $p$ \\
\hline \multicolumn{7}{|c|}{13 and 43} \\
\hline RA & 443 & 47.29 & 15.99 & 20.42 & 87.58 & \\
\hline EA (OF) & 385 & 40.34 & 10.75 & 18.14 & 79.00 & \\
\hline $\mathrm{EA}(\mathrm{BF})$ & 385 & 44.13 & 10.78 & 22.65 & 83.98 & \\
\hline EA (OF) $\times$ RA & 385 & 8.09 & 6.41 & 0.03 & 35.46 & $p=0.001$ \\
\hline$E A(B F) \times R A$ & 385 & 7.85 & 5.60 & 0.03 & 31.57 & $p=0.001$ \\
\hline $\mathrm{EA}(\mathrm{BF}) \times \mathrm{EA}(\mathrm{OF})$ & 385 & 3.79 & 0.21 & 3.32 & 4.99 & $p=0.001$ \\
\hline \multicolumn{7}{|c|}{23 and 33} \\
\hline RA & 443 & 47.29 & 15.99 & 20.42 & 87,58 & \\
\hline EA (OF) & 378 & 39.73 & 10.43 & 17.80 & 74,66 & \\
\hline $\mathrm{EA}(\mathrm{BF})$ & 378 & 43.51 & 10.44 & 22.44 & 79,37 & \\
\hline EA (OF) $\times$ RA & 378 & 7.96 & 6.22 & 0.01 & 38.97 & $p=0.001$ \\
\hline$E A(B F) \times R A$ & 378 & 7.58 & 5.41 & 0.01 & 35.17 & $p=0.001$ \\
\hline $\mathrm{EA}(\mathrm{BF}) \times \mathrm{EA}(\mathrm{OF})$ & 378 & 3.78 & 0.20 & 3.33 & 4.71 & $p=0.001$ \\
\hline
\end{tabular}

13: Upper right canine; 23: Upper left canine; 33: Lower left canine; 43: Lower right canine; SD: Standard deviation; Min: Minimum; Max: Maximum; RA: Real age; EA: Estimated age; OF: Original formula; BF: Brazilian formula.

and compared to the RA of 44.60 years, the mean estimated age was 44.46 years.

The highest mean errors were found in the periapical radiographs of the group aged 20-29 years and in the elderly groups (60-69 and 70-79 years). The best results were found in the groups aged 30-39, 40-49, and 50-59 years, and the mean bias varied from 5.75 $(\mathrm{SD}=4.17)$ to $8.20(\mathrm{SD}=4.91)$ years. These results are similar to a previous study, ${ }^{12}$ but they differ from another report, ${ }^{24}$ which showed a higher level of accuracy in a group aged 21 to 30 years $(S D=0.22)$. Age estimation methods that evaluate morphologic variations using regression models usually have an "attraction to the middle": a trend of having a higher bias at the extremities (younger and older individuals). ${ }^{26}$

The results of this study show that although the Brazilian formula yielded better results than the original formula, its capacity for determining age estimates close to the RA was lower than those obtained in other studies that used the same technique. ${ }^{14,20,21,22}$ One reason could be that most studies used osteological collections as samples, and radiographic images were taken exclusively for these studies with no interference from either soft tissues or other teeth. In our study, periapical radiographs were taken as part of routine dental examinations for treatment reasons. Furthermore, the technique is easily applied to the Legal Medical Institutes after proper training. The associated costs are also low for taking periapical $\mathrm{X}$-rays and having access to a computer with Adobe ${ }^{\circledast}$ Photoshop ${ }^{\circledR}$ CS5.

Other factors that might have influenced the results are individual variations in dental morphology, variation in secondary dentin deposits between individuals, and image biases resulting from the position of the patient or X-ray beam.

Additionally, periapical radiographs are 2-dimensional images of 3-dimensional structures. Therefore, another possible method is to volumetrically analyze dental structures using tomography. ${ }^{16}$

Although the radiographic evaluation of secondary dentin deposits was not the most accurate technique for estimating age in living adults, it is still the best non-invasive technique available. ${ }^{4,19}$ To increase precision, other teeth and more data points could be used to develop multiple regression models.

A challenge for age estimation studies is the standardization of techniques because several different methods have been published. Schmeling et al. ${ }^{1}$ noted that all collected data should be analyzed using appropriate statistical methods because they may influence the results.

This study cannot be applied to edentulous persons and to those with poor oral health. ${ }^{3,7}$ In addition, 
Table 3. Comparisons between the real age (RA) and age obtained using the Brazilian formula (BF) among the age groups.

\begin{tabular}{|c|c|c|c|c|c|c|c|}
\hline Age group & Variables & $\mathrm{n}$ & Mean & SD & Min & Max & $p$ \\
\hline \multirow[t]{6}{*}{$20-29$} & 13 EA (BF) X RA & 80 & 9.91 & 5.52 & 0.97 & 23.08 & 0.001 \\
\hline & $23 \mathrm{EA}(\mathrm{BF}) \times \mathrm{RA}$ & 80 & 9.38 & 5.84 & 0.02 & 23.96 & 0.001 \\
\hline & $33 \mathrm{EA}(\mathrm{BF}) \times \mathrm{RA}$ & 80 & 11.04 & 6.92 & 0.02 & 29.62 & 0.001 \\
\hline & 43 EA (BF) X RA & 80 & 10.64 & 7.53 & 0.03 & 29.63 & 0.001 \\
\hline & Right $E A(B F) \times R A$ & 80 & 9.37 & 5.33 & 0.42 & 24.06 & 0.001 \\
\hline & Left EA (BF) X RA & 80 & 9.07 & 5.40 & 0.32 & 25.02 & 0.001 \\
\hline \multirow[t]{6}{*}{$30-39$} & $13 \mathrm{EA}(\mathrm{BF}) \times \mathrm{RA}$ & 80 & 8.20 & 4.91 & 0.15 & 19.75 & 0.001 \\
\hline & $23 \mathrm{EA}(\mathrm{BF}) \times \mathrm{RA}$ & 80 & 7.05 & 5.09 & 0.61 & 22.06 & 0.001 \\
\hline & $33 \mathrm{EA}(\mathrm{BF}) \times \mathrm{RA}$ & 80 & 7.14 & 5.21 & 0.03 & 21.60 & 0.001 \\
\hline & $43 \mathrm{EA}(\mathrm{BF}) \times \mathrm{RA}$ & 80 & 7.66 & 5.15 & 0.24 & 22.52 & 0.001 \\
\hline & Right EA (BF) X RA & 80 & 6.53 & 4.13 & 0.13 & 19.50 & 0.001 \\
\hline & Left EA (BF) X RA & 80 & 5.75 & 4.17 & 0.01 & 17.81 & 0.001 \\
\hline \multirow[t]{6}{*}{$40-49$} & $13 \mathrm{EA}(\mathrm{BF}) \times \mathrm{RA}$ & 80 & 6.47 & 4.83 & 0.16 & 20.49 & 0.001 \\
\hline & $23 \mathrm{EA}(\mathrm{BF}) \times \mathrm{RA}$ & 80 & 6.25 & 4.27 & 0.24 & 19.76 & 0.001 \\
\hline & $33 \mathrm{EA}(\mathrm{BF}) \times \mathrm{RA}$ & 80 & 6.87 & 4.69 & 0.20 & 19.61 & 0.001 \\
\hline & $43 \mathrm{EA}(\mathrm{BF}) \times \mathrm{RA}$ & 80 & 6.47 & 4.51 & 0.03 & 18.40 & 0.001 \\
\hline & Right EA (BF) X RA & 80 & 6.22 & 4.24 & 0.03 & 18.38 & 0.001 \\
\hline & Left EA (BF) X RA & 80 & 6.08 & 4.04 & 0.21 & 18.94 & 0.001 \\
\hline \multirow[t]{6}{*}{$50-59$} & 13 EA (BF) X RA & 80 & 8.08 & 5.68 & 0.15 & 30.07 & 0.001 \\
\hline & $23 \mathrm{EA}(\mathrm{BF}) \times \mathrm{RA}$ & 80 & 7.63 & 5.98 & 0.04 & 27.53 & 0.001 \\
\hline & $33 \mathrm{EA}(\mathrm{BF}) \times \mathrm{RA}$ & 80 & 7.22 & 6.23 & 0.11 & 35.79 & 0.001 \\
\hline & $43 \mathrm{EA}(\mathrm{BF}) \times \mathrm{RA}$ & 80 & 6.80 & 5.97 & 0.20 & 27.16 & 0.001 \\
\hline & Right EA (BF) X RA & 80 & 7.79 & 5.85 & 0.06 & 27.25 & 0.001 \\
\hline & Left EA (BF) X RA & 80 & 8.07 & 5.78 & 0.09 & 28.57 & 0.001 \\
\hline \multirow[t]{6}{*}{$60-69$} & $13 \mathrm{EA}(\mathrm{BF}) \times \mathrm{RA}$ & 48 & 9.12 & 6.37 & 0.09 & 29.91 & 0.001 \\
\hline & $23 \mathrm{EA}(\mathrm{BF}) \times \mathrm{RA}$ & 44 & 8.70 & 5.93 & 0.10 & 22.85 & 0.001 \\
\hline & $33 \mathrm{EA}(\mathrm{BF}) \times \mathrm{RA}$ & 79 & 7.80 & 5.71 & 0.16 & 26.27 & 0.001 \\
\hline & $43 \mathrm{EA}(\mathrm{BF}) \times \mathrm{RA}$ & 79 & 7.00 & 5.87 & 0.12 & 24.49 & 0.001 \\
\hline & Right EA (BF) X RA & 47 & 8.77 & 6.52 & 0.22 & 28.41 & 0.001 \\
\hline & Left EA (BF) X RA & 41 & 8.43 & 5.54 & 0.37 & 23.79 & 0.001 \\
\hline \multirow[t]{6}{*}{$70+$} & $13 \mathrm{EA}(\mathrm{BF}) \times \mathrm{RA}$ & 18 & 14.60 & 8.18 & 2.32 & 32.81 & 0.001 \\
\hline & $23 \mathrm{EA}(\mathrm{BF}) \times \mathrm{RA}$ & 19 & 13.84 & 8.01 & 1.37 & 30.08 & 0.001 \\
\hline & $33 \mathrm{EA}(\mathrm{BF}) \times \mathrm{RA}$ & 39 & 12.48 & 7.74 & 0.19 & 38.57 & 0.001 \\
\hline & $43 \mathrm{EA}(\mathrm{BF}) \times \mathrm{RA}$ & 42 & 13.09 & 8.85 & 0.01 & 38.69 & 0.001 \\
\hline & Right EA (BF) X RA & 18 & 12.68 & 9.09 & 0.06 & 31.57 & 0.001 \\
\hline & Left EA (BF) X RA & 17 & 12.31 & 8.61 & 2.23 & 35.17 & 0.001 \\
\hline
\end{tabular}

13: Upper right canine; 23: Upper left canine; 33: Lower left canine; 43: Lower right canine; SD: Standard deviation; Min: Minimum; Max: Maximum; RA: Real age; EA: Estimated age; OF: Original formula; BF: Brazilian formula. 
it is necessary to highlight that aging is a biological process and increases the variability of dental features, which change over time.

The technique outlined here is also limited by the location of the reference points, which outlined the tooth and pulp. Therefore, new tools and software could be developed to improve the measurement accuracy at these locations.

In this study, we used periapical radiographs to measure dentin deposits and study their correlation to age in Brazilian adults. The technique can be used to estimate age after considering the limitations that were outlined above.

One limitation is intra- and inter-observer subjectivity, which could be resolved with proper training. Another limitation is that in adults it is difficult to estimate age with precision based on $x$-ray techniques, unlike age estimates in children and adolescents. Additional studies are necessary to develop more accurate meth-

\section{References}

1. Schmeling A, Geserick G, Reisinger W, Olze A. Age estimation. Forensic Sci Int. 2007 Jan 17;165(2-3):178-81.

2. Schmeling A, Grundmann C, Fuhrmann A, Kaatsch HJ, Knell B, Ramsthaler F, et al. Criteria for age estimation in living individuals. Int J Legal Med. 2008 Nov;122(6):457-60.

3. Cunha E, Baccino E, Martrille L, Ramsthaler F, Prieto J, Schuliar $\mathrm{Y}$, et al. The problem of aging human remains and living individuals: a review. Forensic Sci Int. 2009 Dec 15;193(1-3):1-13.

4. Babshet M, Acharya AB, Naikmasur VG. Age estimation in Indians from pulp/tooth area ratio of mandibular canines. Forensic Sci Int. 2010 Apr 15;197(1-3):125.e1-4.

5. Olze A, Solheim T, Schulz R, Kupfer M, Pfeiffer H, Schmeling A. Assessment of the radiographic visibility of the periodontal ligament in the lower third molars for the purpose of forensic age estimation in living individuals. Int J Legal Med. 2010 Sep;124(5):445-8.

6. Schmeling A, Olze A, Reisinger W, Konig M, Geserick G. Statistical analysis and verification of forensic age estimation of living persons in the Institute of Legal Medicine of the Berlin University Hospital Charite. Leg Med (Tokyo). 2003 Mar;5 Suppl 1:S367-71.

7. Cameriere R, Ferrante L. Canine pulp ratios in estimating pensionable age in subjects with questionable documents of identification. Forensic Sci Int. 2011 Mar 20;206(1-3):132-5.

8. Schmeling A, Olze A, Reisinger W, Geserick G. Forensic age diagnostics of living people undergoing criminal proceedings. Forensic Sci Int. 2004 Sep 10;144(2-3):243-5. ods. The main strength of this study is that we identified the need for age estimation techniques in mixed populations because parameters obtained from other populations may not be suitable for all demographics.

\section{Conclusion}

In conclusion, the method of age estimation based on the correlation between age and the pulp/tooth area ratio in canines showed that this Brazilian formula for age estimation was more accurate than the original formula developed by Cameriere et al. ${ }^{14}$ for this sample of Brazilian adults. Despite the improvements, it is necessary to consider additional factors to refine age estimates in adults.

\section{Acknowledgements}

This work was made possible by funds obtained from CAPES (Coordenação de Aperfeiçoamento de Pessoal de Nível Superior).

9. Kaushal S, Patnaik VVG, Agnihotri G. Mandibular Canines In Sex Determination. J Anat. Soc. India. 2003 Dec;52(2):119-24.

10. Lopes JR, Queiroz SBB, Fernandes MM, Paiva LAS, Oliveira RN. Age estimation by teeth periodontosis and transparency: accuracy of Lamendin's method on a Brazilian sample. Braz J Oral Sci. 2014 Jan-Mar;13(1):17-21.

11. Solheim T, Vonen A. Dental age estimation, quality assurance and age estimation of asylum seekers in Norway. Forensic Sci Int. 2006 May 15;159 Suppl 1:S56-60.

12. Ubelaker DH, Parra RC. Application of three dental methods of adult age estimation from intact single rooted teeth to a Peruvian sample. J Forensic Sci. 2008 May;53(3):608-11.

13. Santoro V, De Donno A, Marrone M, Campobasso CP, Introna F. Forensic age estimation of living individuals: a retrospective analysis. Forensic Sci Int. 2009 Dec 15;193(1-3):129.e1-4.

14. Cameriere R, Ferrante L, Cingolani M. Variations in pulp/ tooth area ratio as an indicator of age: a preliminary study. J Forensic Sci. 2004 Mar;49(2):317-9.

15. Fernandes MM, Tinoco RL, Braganca DP, Lima SH, Francesquini Junior L, Daruge Junior E. Age estimation by measurements of developing teeth: accuracy of Cameriere's method on a Brazilian sample. J Forensic Sci. 2011 Nov;56(6):1616-9.

16. Cameriere R, Ferrante L, Belcastro MG, Bonfiglioli B, Rastelli $\mathrm{E}$, Cingolani M. Age estimation by pulp/tooth ratio in canines by peri-apical X-rays. J Forensic Sci. 2007 Jan;52(1):166-70. 
17. Kvaal SI, Kolltveit KM, Thomsen IO, Solheim T. Age estimation of adults from dental radiographs. Forensic Sci Int. 1995 Jul 28;74(3):175-85.

18. Saxena S. Age estimation of indian adults from orthopantomographs. Braz Oral Res. 2011 May-Jun;25(3):225-9.

19. Cameriere R, De Luca S, Alemán I, Ferrante L, Cingolani M. Age estimation by pulp/tooth ratio in lower premolars by orthopantomography. Forensic Sci Int. 2012 Jan 10;214(1-3):105-12.

20. Cameriere R, Ferrante L, Cingolani M. Precision and reliability of pulp/tooth area ratio (RA) of second molar as indicator of adult age. J Forensic Sci. 2004 Nov;49(6):1319-23.

21. Cameriere R, Ferrante L, Belcastro MG, Bonfiglioli B, Rastelli E, Cingolani M. Age estimation by pulp/tooth ratio in canines by mesial and vestibular peri-apical X-rays. J Forensic Sci. 2007 Sep;52(5):1151-5.

22. Cameriere R, Cunha E, Sassaroli E, Nuzzolese E, Ferrante L. Age estimation by pulp/tooth area ratio in canines: study of a Portuguese sample to test Cameriere's method. Forensic Sci Int. 2009 Dec 15;193(1-3):128.e1-6.

23. Jeevan MB, Kale AD, Angadi PV, Hallikerimath S. Age estimation by pulp/tooth area ratio in canines: Cameriere's method assessed in an Indian sample using radiovisiography. Forensic Sci Int. 2011 Jan 30;204(1-3):209.e1-5.

24. Zaher JF, Fawzy IA, Habib SR, Ali MM. Age estimation from pulp/tooth area ratio in maxillary incisors among Egyptians using dental radiographic images. J Forensic Leg Med. 2011 Feb;18(2):62-5.

25. Peres MA, Barbato PR, Reis SC, Freitas CH, Antunes JL. Tooth loss in Brazil: analysis of the 2010 Brazilian Oral Health Survey. Rev Saude Publica. 2013 Dec;47 Suppl 3:78-89.

26. Prince DA, Konigsberg LW. New formulae for estimating ageat-death in the Balkans utilizing Lamendin's dental technique and Bayesian analysis. J Forensic Sci. 2008 May;53(3):578-87. 